\title{
Microplastics Determination in the Rivers with Different Urbanisation Variances: A Case Study in Kuching City, Sarawak, Malaysia
}

\author{
GEORGINA JOHNSON*, WEN SAN HII, SAMUEL LIHAN \& MENG GUAN TAY \\ Faculty of Resource Science and Technology, Universiti Malaysia Sarawak, 94300 Kota Samarahan, Sarawak, \\ Malaysia \\ *Corresponding author: georginajohnson086@gmail.com \\ Received: 10 August 2020 Accepted: 14 December $2020 \quad$ Published: 31 December 2020
}

\begin{abstract}
The presence of microplastics in aquatic systems is mainly due to the anthropogenic activities such as domestic waste dumping. Undeniably, rivers either in urban or suburban areas are always a waste dumpling sites from the surrounding residences. Thus, the purpose of this study was to determine the relationship between microplastic abundance and different degree of urbanization across Kuching in Sarawak. Three sampling locations with different degrees of urbanisation had been studied across Kuching. A total of 137 pieces of microplastics were collected along the study and analysed using stereoscopic microscope for the shape identification and FTIR spectrophotometer for functional groups present in the microplastics. Filament was the most abundant microplastics shape found, whereas the IR results showed that ethylenevinylacetate $(9 \%)$, polyamides or nylon $(15 \%)$, polypropylene $(42 \%)$, poly(methylmethacrylate) $(16 \%)$ and polystyrene $(18 \%)$ were found in the study. The most abundant microplastics in the water samples was polypropylene $(42 \%)$, whereas ethylenevinylacetate $(9 \%)$ was the least. The degree of urbanisation does not directly relate to the microplastic present in the river system in Kuching City, but the anthropogenic activity is the main factor that affecting the microplastic abundance in the river.
\end{abstract}

Keywords: Anthropogenic activity, FTIR, microplastics, polymer identification, urban, sub-urban

Copyright: This is an open access article distributed under the terms of the CC-BY-NC-SA(Creative Commons Attribution-Non Commercial-Share Alike 4.0 International License) which permits unrestricted use, distribution, and reproduction in any medium, for non-commercial purposes, provided the original work of the author(s) is properly cited.

\section{INTRODUCTION}

The plastic manufacturing industry is one of the most dynamic and vibrant growth sectors in Malaysia. However, in line with the increase of plastic production, the plastic wastes have been recorded the third largest waste tonnage, after the putrescible waste and paper waste (Malaysian Department of Housing and Local Government, 2011).

As plastic particles can be broken into small particle called microplastics, this has prompted public concerns due to high possibility of microplastics flow into the food chain. The abundance of microplastics in aquatic environment as it is highly volatile in mobility ( $\mathrm{Ng} \&$ Obbard, 2006; Gall \& Thompson, 2015; Kwon et al., 2017) and ingested by aquatic organisms and gets into food chain (Yusof et al., 2016; Avio et al., 2017; Yusof et al., 2017; Karami et al., 2017; Smith et al., 2018). Many researchers found that microplastics are more abundant in subtidal sediments and sea waters rather than on sandy beaches and in estuarine habitats (Thompson et al., 2004; Browne et al., 2011; Claessens et al., 2011; Peng et al., 2018; Peng et al., 2019). Thus, the sources of microplastics could origin from the rivers (Shazani et al., 2018) due to irresponsible domestic wastes dumping into the rivers by surrounding communities. Again, this could be also strongly related to the human population as well as the environmental awareness of the surrounding community. Hence, this study was designed to relate the source of microplastics to different degree of urbanization across Kuching City.

\section{MATERIALS AND METHODS}

\section{Sampling Locations and Frequencies}

The river water samples were collected from three areas in Kuching City namely Kuap River (W1) in sub-urban area, Maong River (W2) located in 
urban area and Sarawak River (W3) in Waterfront Kuching, which is an extra urban area. A brief description of the sampling locations with GPS coordinates is stated in Table 1. Figure 1 shows the geographical location of the three stations using Google Earth, Maxar Technologies (2019), whereas Figures $2-4$ show closer views of each sampling location. Three samplings were carried out in October, November and December 2018. The water samples were collected using a water sampler Wildco, Wildco Alpha Bottle Kit 4.2 L) and each sample was then filtered using a membrane filter with $0.45 \mu \mathrm{m}$ pore size.

Table 1. Descriptions of the sampling locations

\begin{tabular}{|c|c|}
\hline Sampling points and GPS coordinates & Descriptions \\
\hline $\begin{array}{l}\text { W1 } \\
\text { Kuap River } \\
1^{\circ} 27^{\prime} 38.39 " \mathrm{~N} \\
110^{\circ} 21^{\prime} 24.28^{\prime \prime} \mathrm{E}\end{array}$ & 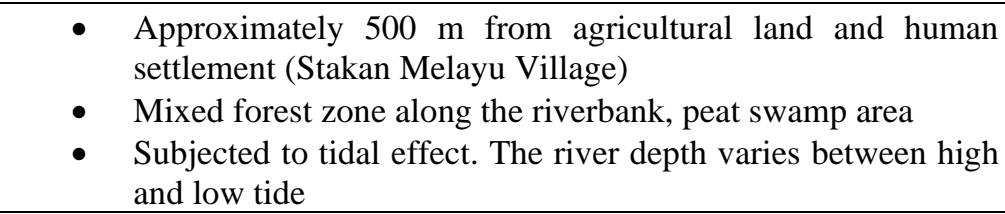 \\
\hline $\begin{array}{l}\text { W2 } \\
\text { Maong River } \\
1^{\circ} 30^{\prime} 43.60 " \mathrm{~N} \\
110^{\circ} 20^{\prime} 25.44^{\prime \prime} \mathrm{E}\end{array}$ & $\begin{array}{l}\text { - High residential density area } \\
\text { - Disposal of grey water into drainages from surrounding } \\
\text { housing area into the river } \\
\text { - } \quad \text { No tidal effect }\end{array}$ \\
\hline $\begin{array}{l}\text { W3 } \\
\text { Sarawak River, Kuching Waterfront } \\
1^{\circ} 33 \text { '30.78"N } \\
110^{\circ} 20^{\prime} 52.60^{\prime \prime} \mathrm{E}\end{array}$ & $\begin{array}{l}\text { - Very high density of human settlement, commercial and } \\
\text { tourism activities } \\
\text { - The river is not subjected to tidal effect }\end{array}$ \\
\hline
\end{tabular}

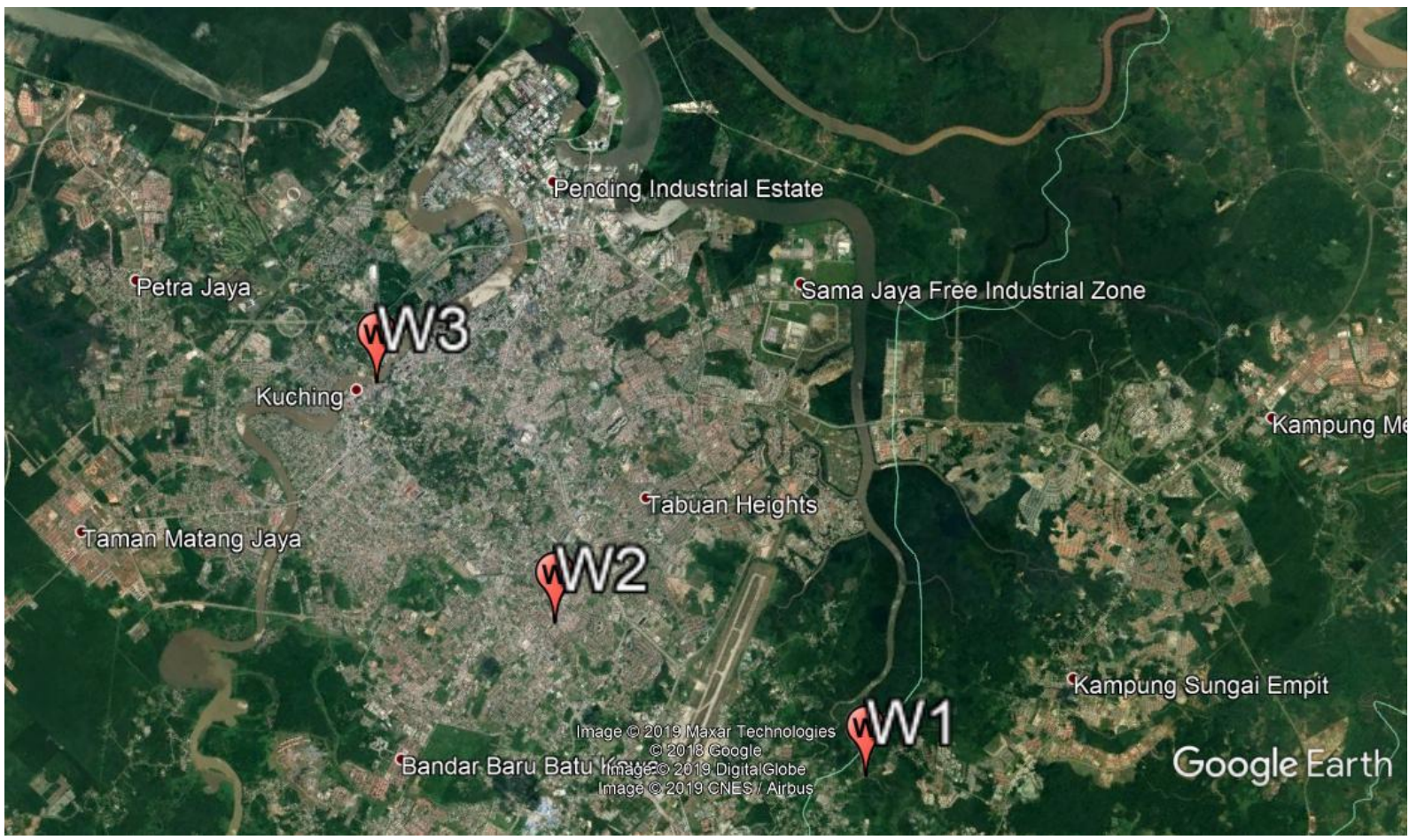

Figure 1. Sampling locations of W1, W2 and W3. (Source: Google Earth, 2019 Maxar Technologies) 


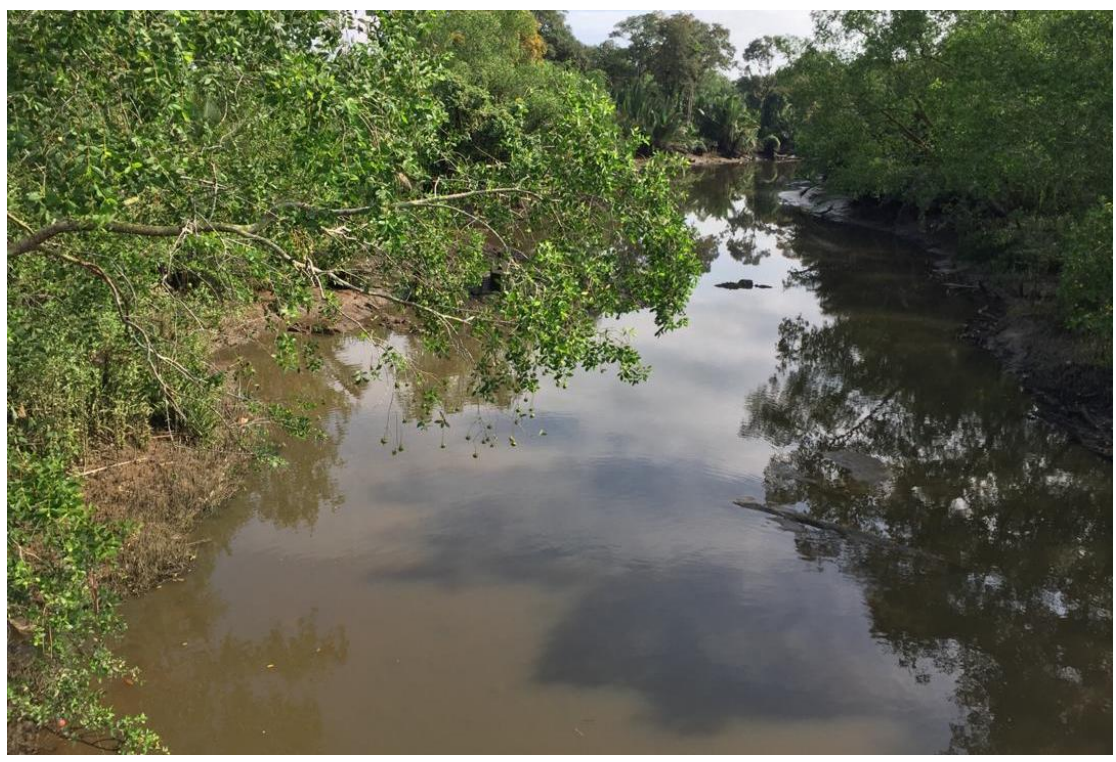

Figure 2. Environmental condition of W1

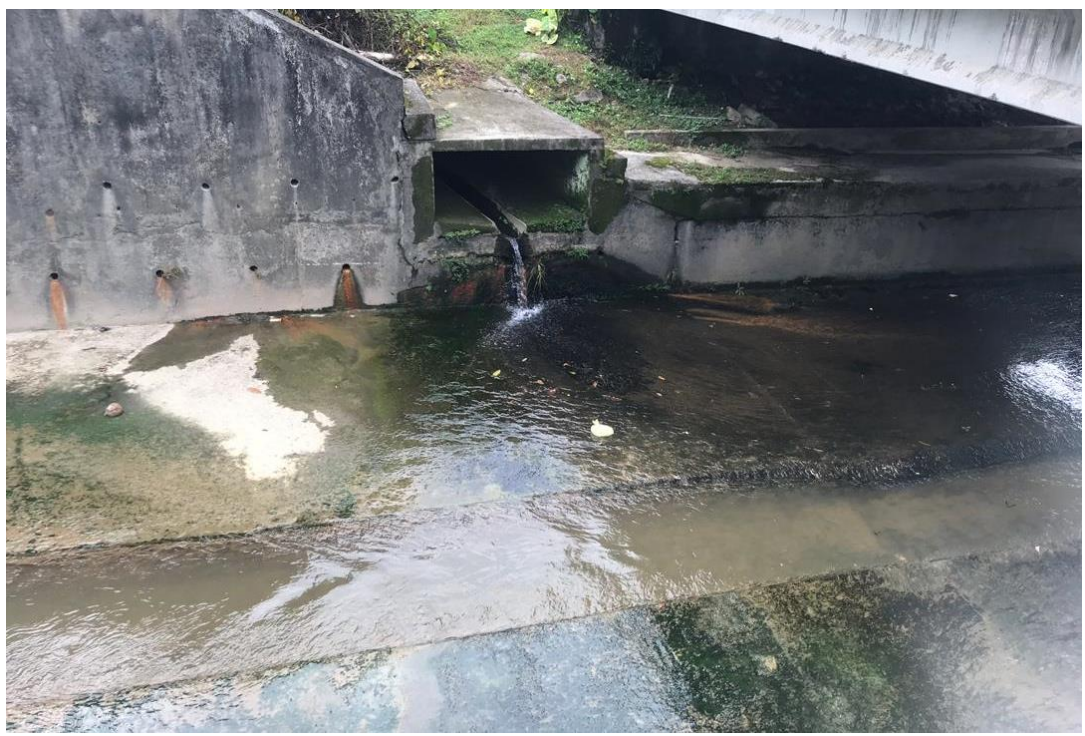

Figure 3. Environmental condition of W2

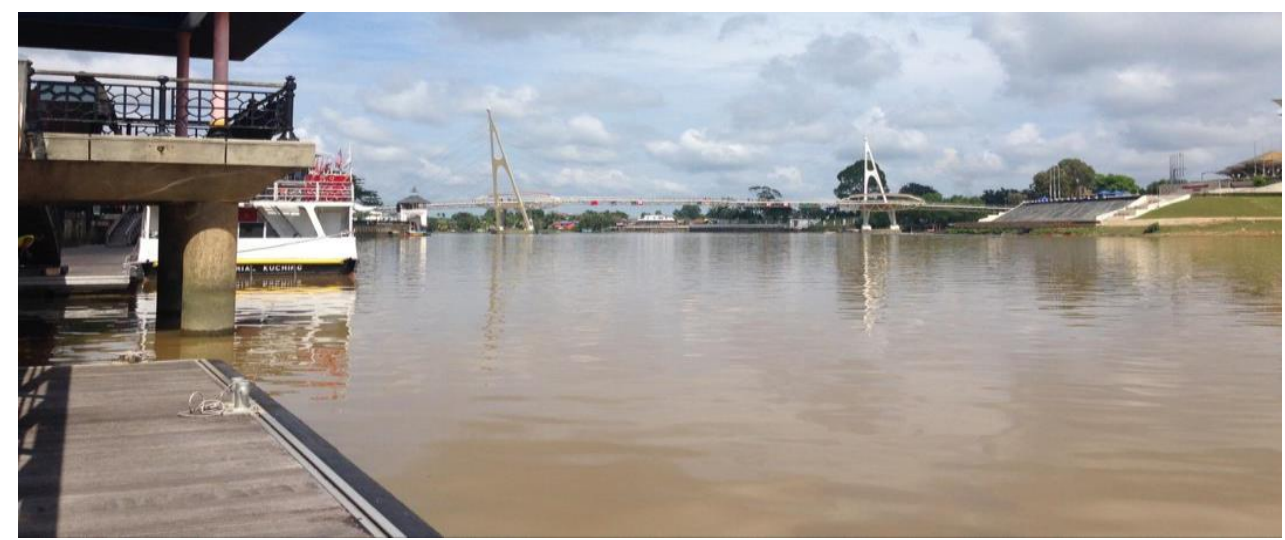

Figure 4. Environment condition of W3 


\section{Wet Peroxide Digestion}

Hydrogen peroxide $(35 \%, 25 \mathrm{ml})$ and ferrous sulphate heptahydrate catalyst solution $(0.05 \mathrm{M}, 25$ $\mathrm{ml}$ ) were added into a beaker which contained the total solids (Zobkov \& Esiukova, 2017). Then, the content in the beaker was heated up to $75^{\circ} \mathrm{C}$ and removed from the hotplate when the gas bubbles were observed. The beaker was cooled in the fume hood and the solution was filtered by using 0.45 $\mu \mathrm{m}$ membrane filter in order to obtain the microplastics particles (Masura et al., 2015).

\section{Microplastic Sorting and Identification}

The membrane filter was viewed under a stereo microscope (Nikon, C-LEDS) at 40X magnification. The microplastics were sorted based on their maximum length, colour and shape (threadlike, fragment or spherical) based on the guidelines as given by Hidalgo-Ruz et al. (2012). The category of microplastic was identified based on the chemical functional groups present in the microplastic using Fourier transform infra-red (FTIR) spectrophotometer (Thermo Scientific, Nicolet $^{\mathrm{TM}} \mathrm{iS}^{\mathrm{TM}}$ 10) with attenuated total reflection (ATR).

\section{RESULTS AND DISCUSSION}

\section{Morphology of the Sampling Sites}

Kuap River was shaded by peat swamp vegetation, mainly mangrove trees, palms and aquatic shrubs along the riverbank. An irresponsible domestic waste dumping site is located at $\mathbf{W 1}$, just at the side of the riverbank (Figure 5). The colour of the river water was murky due to high sediment content that runoff from the riverbank as shown in Figure 2. The current and flow rate of the river were moderately slow and subjected to tidal. The samplings were usually carried out during the low tide due to accessibility to the river water. There is a village located about $1 \mathrm{~km}$ radius of the sampling point and estimated population in the village is about 2,500 -3,000 people (Sarawak Government, 2020).

On the other hand, W2 in Maong River is located at the middle of a densely-populated residential area with estimated population of 10,000-20,000 (Sarawak Government, 2020) (Figure 6). Maong River is not shaded by any vegetation and no riverbank erosion because the river bank surface is covered with concrete cement.
The river serves the purpose of receiving grey and black waters discharge of the kitchens and toilets from urban-residential houses. The colour of the river water was cloudy and the flow was not subjected to tidal but dependent on the weather condition.

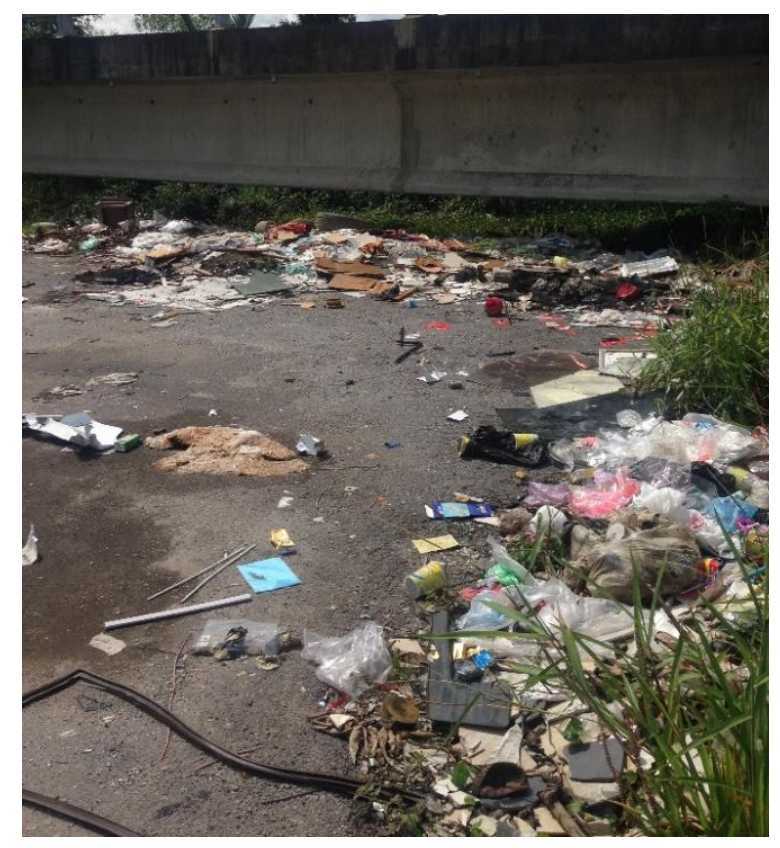

Figure 5. Irresponsible domestic waste dump site at Kuap riverbank

The location of $\mathbf{W} 3$ in Sarawak River is at the heart of Kuching City, which is mainly surrounded with commercial area and recreational park. Until today, Sarawak River is still an important river for Kuching City because the river does not only serve as a main water transportation system in the city but also as a drinking water source for the population living in Kuching City. The colour of the river water was brownish and not subjected to tidal effect due to the bund building at the downstream (Leete, 2008).

\section{Microplastics Abundance}

The total number of microplastics found in all samples were 137 pieces throughout the threemonth study (Figure 7). The abundance levels varied depending on the sampling location. Station W3 in Sarawak River recorded the highest microplastics number, that is 61 pieces consisting filaments (50 pieces), fragments and fibres. Meanwhile, the W1 in Kuap River recorded the second most abundant microplastics found (49 pieces). There were 13 microbeads (Figure 8) identified and 25 filaments (Figure 9), followed by fragments (Figure 10) and the least are fibres. 


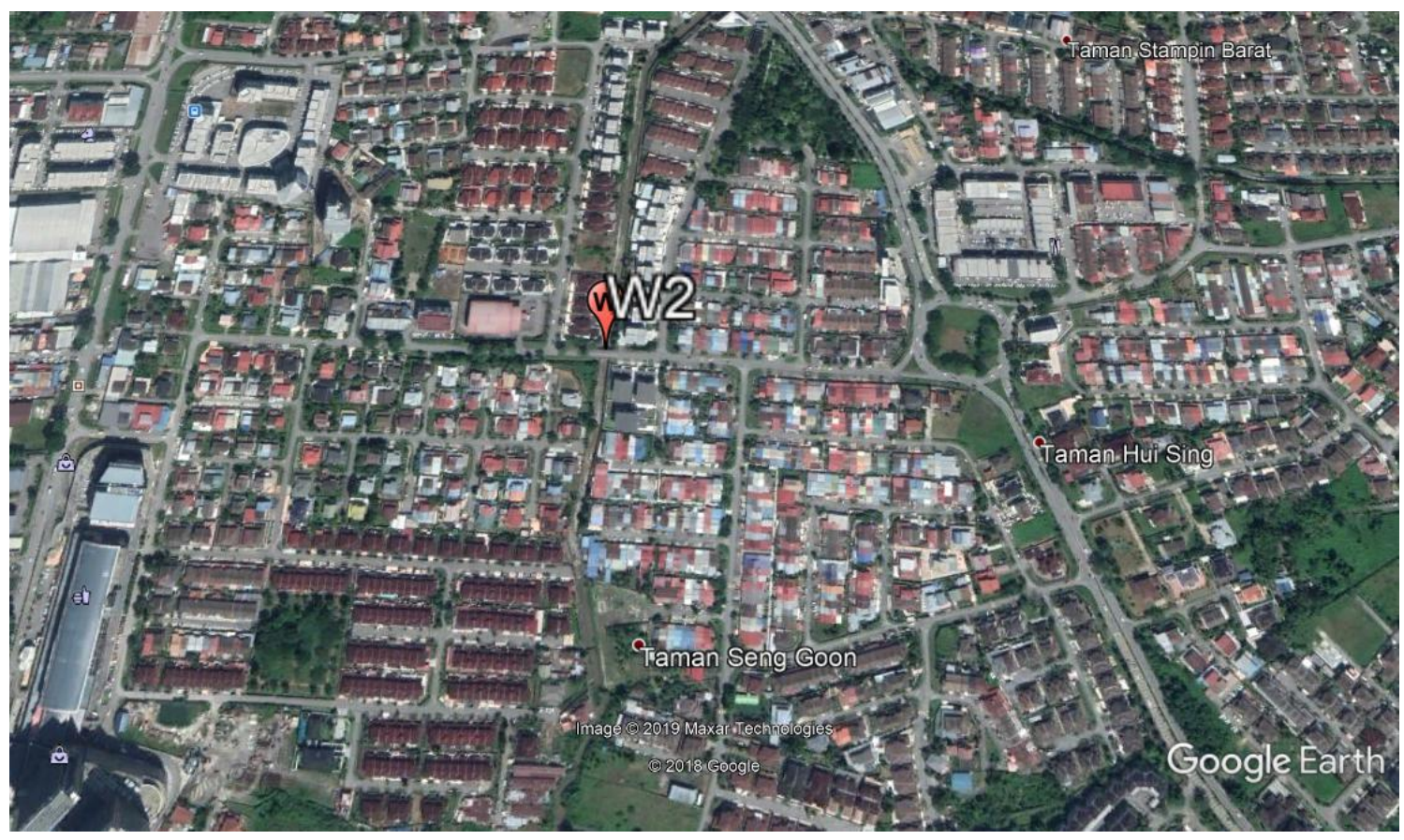

Figure 6. Surrounding condition of W2 (Source: Google Earth, 2019 Maxar Technologies)

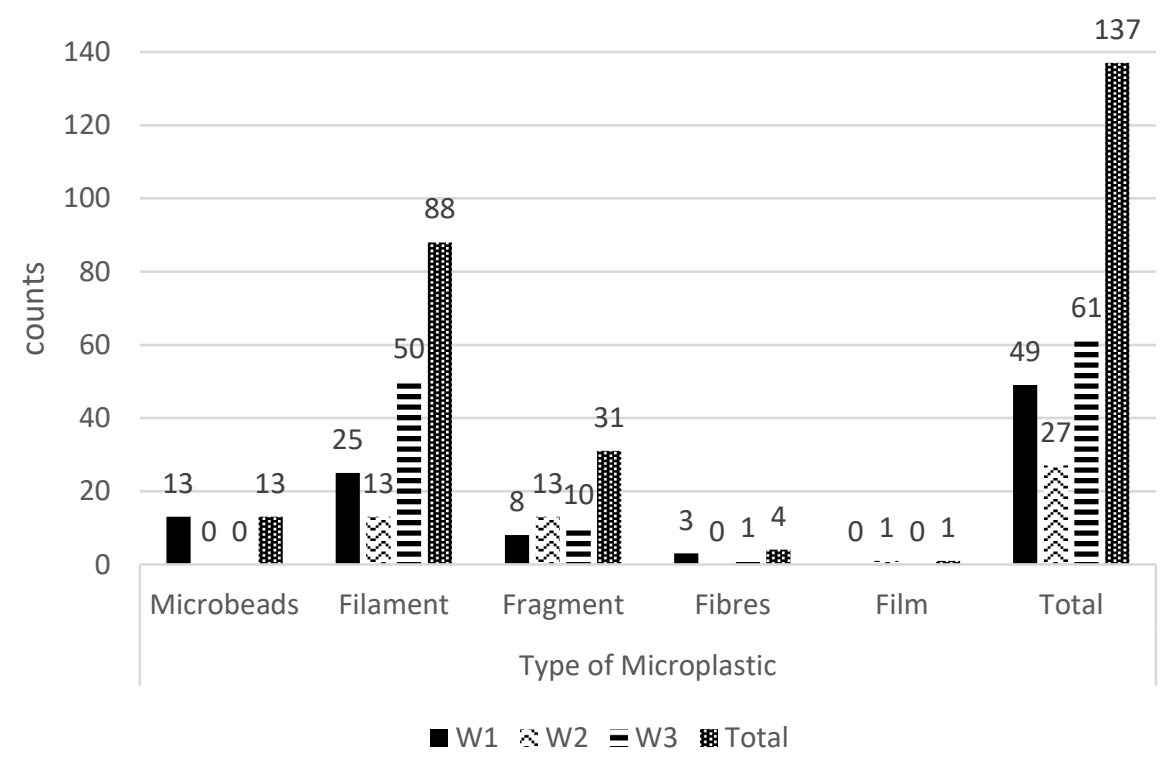

Figure 7. Total number of microplastics from three sampling stations 


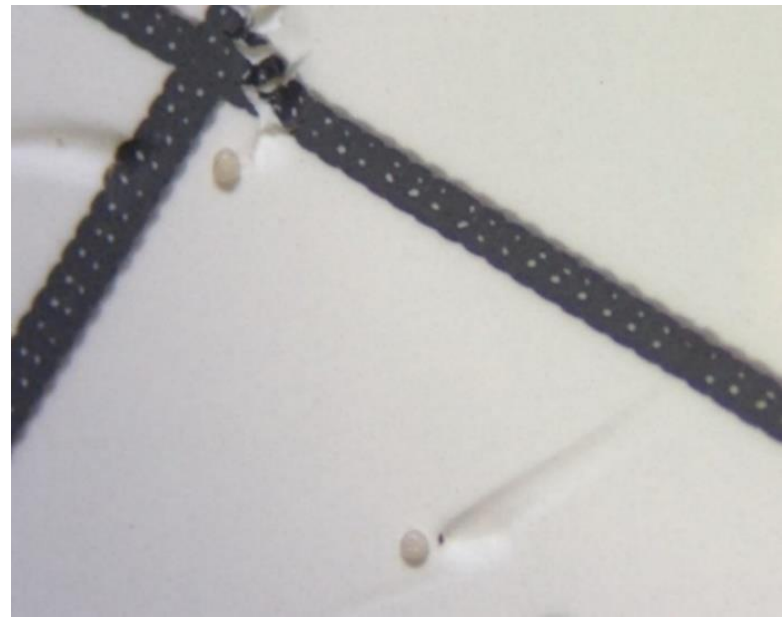

Figure 8. Microbeads found in the water samples from W1 (at 40X magnification)

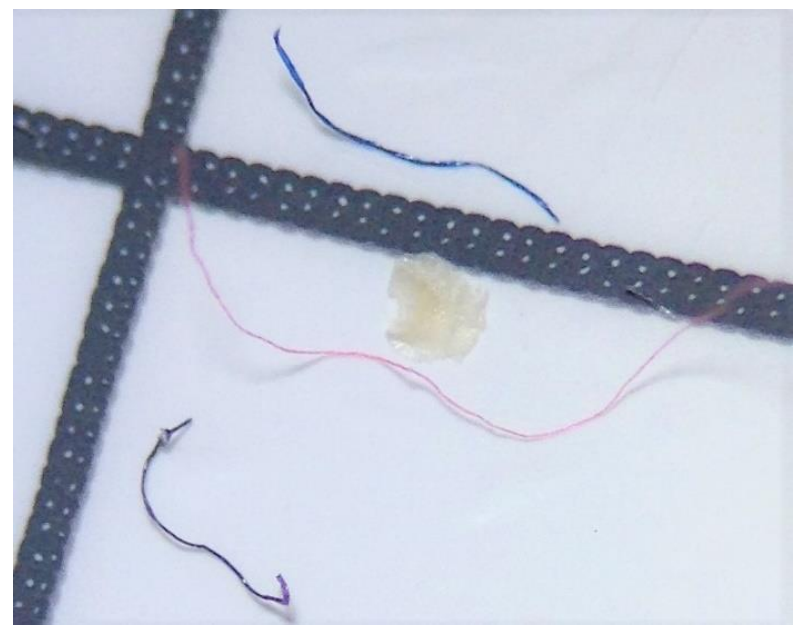

Figure 9. Filaments found in the water sample from W1 (at $40 \mathrm{X}$ magnification)

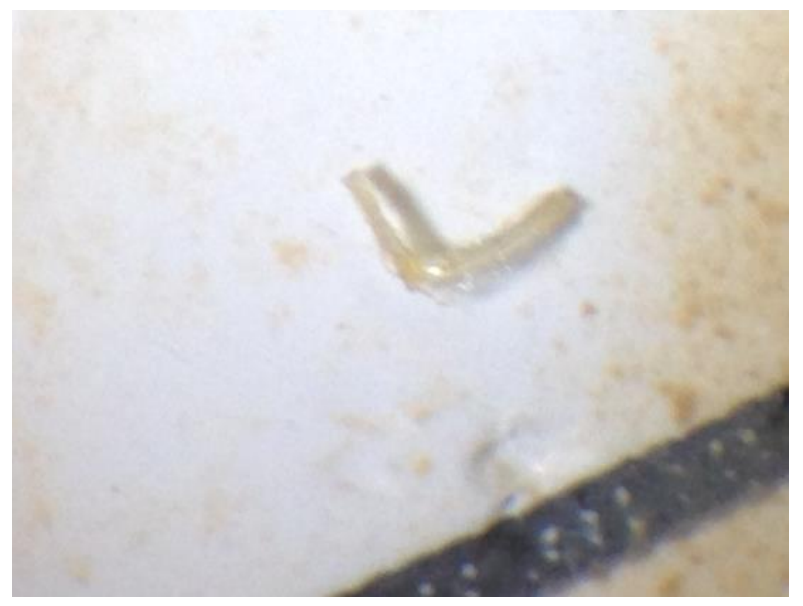

Figure 10. Fragment found in the water sample from W3 (at 40X magnification)
The type of microplastics present in the rivers is dependent on the anthropogenic activities (Kataoka et al., 2019) as well as the residences' environmental awareness. In fact, as shown in Figure 5, irresponsible solid wastes disposal at the river bank of W1 was the main reason why the sample from W1 contained more microplastic debris.

A higher number of filaments from fishing nets were found in Sarawak River (W3) due to the fishing activities along the riverside. For W3, solid waste disposal from commercial river cruises and fishing boats have contributed to the high amount of garbage stranded on the riverbank. As Sarawak River is one of the earliest settlement areas in Sarawak with high human population and industrial factories, it was expected that the anthropogenic impact in $\mathbf{W} \mathbf{3}$ would be much greater than W1 and W2. Lastly, W2, which is located in an urban housing area, had the lowest number of microplastics collected, in which the presence of microplastics in this area could be due to the discharge of grey waters from toilets and kitchens. In 2019, Dikareva and Simon found the variation in the quantity and type of plastic occurring in small streams. Similar to our study, their results showed that the most abundant microplastics were fragments and small particles (63-500 $\mu \mathrm{m})$.

In general, it was observed that the sources of plastic flow into the river can be due to surrounding community' anthropogenic activities, the discharge of greywater from kitchen and irresponsible solid waste dumping at the river bank. These results were in line with the findings from Kataoka et al. (2019), where the group noticed that the anthropogenic activities near the river were the main contribution to the microplastics present in the river in Japan. However, in contrast to our findings, the group noticed that the degree of urbanization was significantly related to abundance of microplastics present in the river.

\section{Microplastic classification}

The classification of microplastics were performed using a FTIR spectrophotometer with an ATR adapter. The list of functional groups found in the IR spectra from the microplastic samples are tabulated in Table 2 and some examples of IR spectra for different plastic are shown in Figures 11-12. 
Table 2. The list of functional groups with the respective IR frequencies $\left(\mathrm{cm}^{-1}\right)$ present in the microplastic samples

\begin{tabular}{lccccc} 
& \multicolumn{5}{c}{ Chemical functional groups in respective frequency } \\
\hline Plastic type & vN-H & vC-H & vC=O & vC=C & vC-O \\
\hline Ethylenevinylacetate (EVA) & - & 3051 & 1774 & - & 1027 \\
Polyamides (PA) / nylon & 3696 & 2961 & 1642 & - & - \\
Polypropylene (PP) & - & 2951 & - & - & - \\
Polymethylmethacrylate (PMMA) & - & 2952 & 1711 & - & 1168 \\
Polystyrene (PS) & - & 2838 & - & 1601 & - \\
\hline
\end{tabular}

Note: "_" means not available

Ethylenevinylacetate (EVA) was identified based on the strong IR peak located at $3051 \mathrm{~cm}^{-1}$ which is attributed to $\mathrm{C}-\mathrm{H}$ vibration of alkane group. Meanwhile, the IR signals at 1774 and 1027 $\mathrm{cm}^{-1}$ are corresponding to the $\mathrm{C}=\mathrm{O}$ and $\mathrm{C}-\mathrm{O}$ stretching, respectively. For polyamides (PA), which is also well known as nylon, the weak peak at $3696 \mathrm{~cm}^{-1}$ is attributed to $\mathrm{N}-\mathrm{H}$ vibration from the amine group [Figure 11(a)]. Meanwhile, the strong IR frequency at $2961 \mathrm{~cm}^{-1}$ is due to the $\mathrm{C}-\mathrm{H}$ vibration and the band at $1642 \mathrm{~cm}^{-1}$ correspond to the $\mathrm{C}=\mathrm{O}$ stretching mode (Figure 11a). It is worth to note that the $\mathrm{C}=\mathrm{O}$ absorption of amides normally present at lower frequency than typical carbonyl group due to the resonance effect along the molecule.

For polypropylene (PP), since the molecule only contains long alkane chain, thus the only IR frequency can be observed is at $2951 \mathrm{~cm}^{-1}$ [Figure 11(b)]. Polypropylene is particularly prevalent in the environment due to their production in vast quantity for packaging applications such as candy wrappers, disposable food containers, and drinking water bottles.

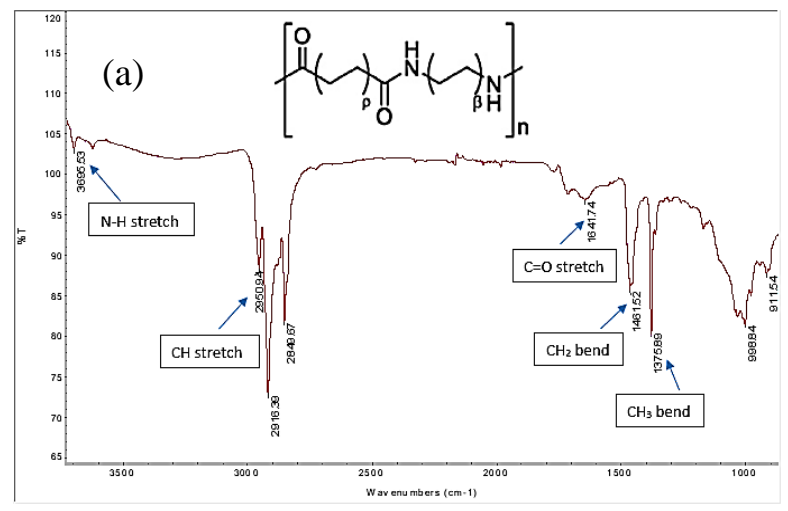

The structure of PMMA can be characterised by the IR frequency at $1766 \mathrm{~cm}^{-1}$ (Figure 12) due to the $\mathrm{C}=\mathrm{O}$ stretching of carboxyl group (Duan et al., 2008). A group of weak IR frequencies at the region of 1101 to $1167 \mathrm{~cm}^{-1}$ is attributed to the $\mathrm{C}$ $\mathrm{O}$ stretching mode supporting the presence of $\mathrm{O}=\mathrm{C}$ $\mathrm{O}$ group in PMMA. Meanwhile, another two IR bands at 2951 and $2916 \mathrm{~cm}^{-1}$ are assigned to the C$\mathrm{H}$ vibrations due to the alkane chain in the PMMA structure.

Another type of plastic, which has been widely used in food packing called polystyrene (PS) was also found in the samples. The micro size PS is the debris from a larger size PS due to natural weathering (Wu et al., 2017; Wirnkor et al., 2019). From the prospect of IR analysis, this type of plastic can be characterised by determining the aromatic $\mathrm{C}=\mathrm{C}$ stretching at $1601 \mathrm{~cm}^{-1}$ as well as the $\mathrm{C}-\mathrm{H}$ vibration at $2838 \mathrm{~cm}^{-1}$.

Based on the numbers shown in Table 3, PP is the most abundant microplastics (42\%) found in the samples, followed by PS (18\%), whereas PMMA and PA accounting for 16 and 15\%, respectively.

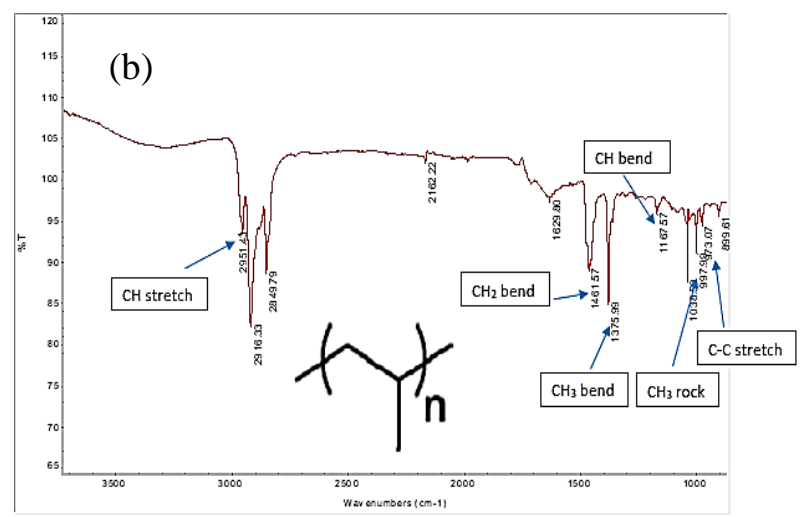

Figure 11. IR spectra of (a) polyamides (PA) or nylon, and (b) polypropylene (pp) that found in the water samples 


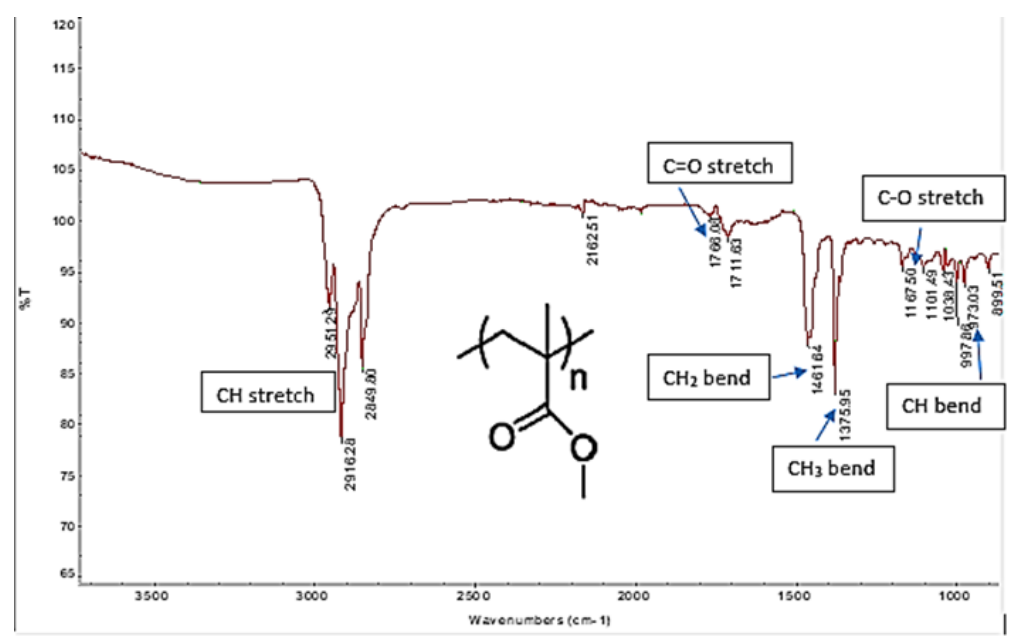

Figure 12. The IR spectrum of poly(methylmethacrylate), PMMA

Table 3. Distributions of microplastics (\%) found in the three sampling locations

\begin{tabular}{ccccc}
\hline & W1 & W2 & W3 & Abundance \\
\hline EVA & 28 & 0 & 0 & 9 \\
PS & 5 & 45 & 3 & 18 \\
PA & 10 & 23 & 13 & 15 \\
PP & 57 & 5 & 63 & 42 \\
PMMA & 0 & 27 & 21 & 16 \\
\hline
\end{tabular}

Lastly, EVA was recorded as 9\% abundance in overall collected samples. PP was recorded with the highest abundance from Sarawak River (W3). Due to light density nature of PP $\left(0.90-0.91 \mathrm{~g} / \mathrm{cm}^{3}\right)$, the plastic always floats on the water surface and exposed under the sun which promotes the breakdown of plastic into small debris. Due to this reason, the amount of this plastic found was dominant in the sample (Hidalgo-Ruz et al., 2012). The second most abundance plastic namely PMMA was found in Maong (W2) and Sarawak (W3) Rivers, whereas both PA and PS were found in three study sites especially W2 (Table 3).

\section{CONCLUSION}

Most of the microplastic debris were found in W3 located at Sarawak River with the type of filament, which has been identified as polypropylene (PP). As can be seen from the results of sampling points in $\mathbf{W 1}$ and $\mathbf{W} \mathbf{2}$, the degree of urbanization was not directly related to the microplastics present in the rivers in Kuching City. The anthropogenic activity is the main factor that affects the microplastics abundance in the river. Nevertheless, we also highlight that the solid waste dumpling site next to the Kuap River has contributed significant the microplastic abundance to the river. The solid waste dumpling site is resulted from the low environmental awareness and irresponsible activity from the human.

\section{ACKNOWLEDGMENT}

The financial support through MyRA Special Grant Scheme [F07/SpGS/1549/2017] from Universiti Malaysia Sarawak is gratefully acknowledged.

\section{REFERENCES}

Avio, C.G., Gorbi, S. \& Regoli, F. (2017). Plastics and microplastics in the oceans: From emerging pollutants to emerged threat. Marine Environmental Research, 128, 2-11.

Browne, M. A., Crump, P., Niven, S. J., Teuten, E., Tonkin, A., Galloway, T. \& Thompson, R.C. (2011). Accumulations of microplastic on shorelines worldwide: sources and sinks. Environmental Science Technology, 45: 9175-9179. 
Claessens, M., De Meester, S., Van Landuyt, L., De Clerck, K., \& Janssen, C. R. (2011). Occurrence and distribution of microplastics in marine sediments along the Belgian coast. Marine Pollution Bulletin, 62: 2199-2204.

Dikareva, N. \& Simon, K. S. (2019). Microplastic pollution in streams spanning an urbanization gradient. Environmental Pollution, 250: 292-299.

Duan, G., Zhang, C., Li, A., Yang, X., Lu, L., \& Wang, X. (2008). Preparation and characterization of Mesoporous Zirconia made by using a poly(methyl methacrylate) template. Nanoscale Research Letter, 3: $118-122$.

Gall, S. C., \& Thompson, R. C. (2015). The impact of debris on marine life. Marine Pollution Bulletin, 92 $170-179$.

Hidalgo-Ruz, V., Gutow, L., Thompson, R. C., \& Thiel, M. (2012) Microplastics in the marine environment: A review of the methods used for identification and quantification. Environment Science Technology, 46: 3060-3075.

Karami, A., Golieskardi, A., Ho, Y. B., Larat, V., \& Salamatinia, B. (2017). Microplastic in eviscerated flesh and excised organs of dried fish. Scientific Reports, 7: 5473. https://doi.org/10.1038/s41598017-05828-6.

Katoka, T., Nihei, Y., Kudou, K. \& Hinata, H. (2019). Assessment of the sources and inflow processes of microplastics in the river environments of Japan. Environmental Pollution, 244(1): 958-965.

Kwon, J. -H., Chang, S., Hong, S. H., \& Shim, W. J. (2017). Microplastics as a vector of hydrophobic environment: importance of hydrophobic additives. Integrated Environmental Assessment and Management, 13: 494-499.

Leete, R., (2008). Malaysia Inland Waterway: Transportation System in Sarawak. United Nations Development Programme (UNDP), Kuala Lumpur, Malaysia. ISBN 983-3904-07-5.

Malaysian Department of Housing and Local Government (2011). A study on plastic management in Peninsular Malaysia-Final Report. Golden Ecosystem Sdn. Bhd.

Masura, J., Baker, J., Foster, G. \& Sadri, C. (2015). Laboratory methods for the analysis of microplastics in the marine environment: recommendations for quantifying synthetic particles in waters and sediments. NOAA Technical Memorandum NOS-OR\&R-48.

Ng, K.L. \& Obbard, J.P. (2006). Prevalence of microplastic in Singapore's coastal marine, Marine Pollution Bulletin, 52: 761-767.

Peng, G., Xu, P., Zhu, B., Bai, M. \& Li, D. (2018). Microplastics in freshwater river sediments in Shanghai, China: A case study of risk assessment in mega-cities. Environmental Pollution, 234: 448-456.

Peng, L., Fu, D., Qi, H., Lan, C.Q., Yu, H. \& Ge, C. (2019). Micro- and nanoplastics in marine environment: Source, distribution and threats - A review. Science of the Total Environment, 698 134254.

Sarawak Government. (2020). Sarawak Population. Retrieved November 18, 2020, from https://www.sarawak.gov.my/web/home/article_vie w/240/175/.

Shazani, S., Azman, S., Mohd Ismid Mohd Said, Yusrina Andu \& Nur Farhan. (2018). Microplastics in sediment from Skudai and Tebrau river, Malaysia: a preliminary study. MATEC Web of Conferences, 250(1): 06012.

Smith, M., Love, D. C., Rochman, C. M. \& Neff, R. A. (2018). Microplastics in Seafood and the Implications for Human Health. Current Environmental Health Reports, 5(3): 375-386.

Thompson, R. C., Olsen, Y., Mitchell, R. P., Davis, A., Rowland, S. J., John, A. W. G., McGonigle, D., \& Russell, A. E. (2004). Lost at sea: Where is all the plastic? Science, 304: 838.

Wirnkor, V. A., Ebere, E. C. \& Ngozi, V. E. (2019) Microplastics, an emerging concern: A review of analytical techniques for detecting and quantifying microplatics. Analytical Methods in Environmental Chemistry, 2(2): 15-32.

Wu, C. X., Zhang, K. \& Xiong, X. (2017). Microplastic Pollution in Inland Waters Focusing on Asia. Freshwater Microplastics, 58: 85-99.

Yusof, S. I., Alyza, A. A., Shaakirah, A. S., Sabiqah, T. A., \& Siti, A. A. (2016). Microplastics ingestion by Scapharca cornea at Setiu Wetland, Terengganu, Malaysia. Middle-East Journal of Science Research, 24: 2129-2136.

Yusof, S. I., Ruthra R., Sabiqah T. A., \& Afiq W. M. W. M. K., (2017) Isolation and characterization of microplastic abundance in Lates calcarifer from 
Setiu Wetland, Malaysia. Malaysian Journal of Analytical Science, 21: 1054-1064.

Zobkov, M. \& Esiukovw, E. (2017). Microplastics in Baltic bottom sediments: Quantification procedures and first results. Marine Pollution Bulletin, 114(2): 724-732. 